\title{
Prevalence and determinants of gender- based violence among high school female students in Wolaita Sodo, Ethiopia: an institutionally based cross-sectional study
}

Temesgen Tantu', Sintayehu Wolka², Muluken Gunta ${ }^{3}$, Million Teshome ${ }^{4}$, Hangatu Mohammed ${ }^{2}$ and Bereket Duko ${ }^{5,6^{*}}$

\begin{abstract}
Background: Gender-based violence (GBV) often occurs in resource-limited settings such as Ethiopia. It could result in psychological and physical adverse outcomes such as stress, anxiety, depression, unsafe abortion, unwanted pregnancy, and sexually transmitted infections. This study aimed to assess the prevalence and factors associated with gender-based violence among female high school students in Wolaita Sodo, Ethiopia.

Methods: An institutionally based-cross-sectional study was conducted in Wolaita Sodo, Ethiopia. A total of 604 female high school students were recruited through multi-stage stratified sampling techniques. The gender-basedviolence assessment tool, validated by the World Health Organization, was used to assess gender-based-violence and other determinants. The strength of statistical association was measured by adjusted odds ratios and $95 \%$ confidence intervals. Statistical significance was declared at $p$-value $<0.05$.

Results: The lifetime prevalence of GBV, sexual violence, and physical violence were found to be 63.2, 37.2, and 56.3\%, respectively. The prevalence of sexual violence before and after joining the current school as well as in the current academic year were 30.5, 37.2, and 22\% respectively. Having regular boy-friends (AOR $=2.02 ; 95 \%$ Cl:1.07-3.79), being sexually active (AOR $=6.10 ; 95 \% \mathrm{Cl}: 2.49-14.92)$, having female or male friends who drink alcohol (AOR $=2.18 ; 95 \% \mathrm{Cl}$ : 1.26-3.77), students witnessed their mothers being beaten by their partners or husband (AOR $=1.92 ; 95 \% \mathrm{Cl}: 1.19-3.11$ ) and joining public school ( $\mathrm{AOR}=1.74 ; 95 \% \mathrm{Cl}: 1.11-2.76)$ were significantly associated with gender-based violence.

Conclusion: The prevalence of gender-based-violence was high. This needs a due concern from governmental, nongovernmental and civic organizations as well as other responsible bodies to tackle factors associated with GBV in this study. Further large scale studies incorporating male students are warranted to elucidate the factors associated with GBV in Ethiopia.
\end{abstract}

Keywords: Gender-based violence, Female, High school, Students, Wolaita Sodo, Ethiopia

\footnotetext{
* Correspondence: berkole.dad@gmail.com

${ }^{5}$ Faculty of Health Sciences, College of Medicine and Health Sciences, Hawassa University, Hawassa, Ethiopia

${ }^{6}$ School of Public Health, Curtin University, Perth, Australia

Full list of author information is available at the end of the article
}

\section{Background}

Gender-based violence (GBV) is not only referring to the use of one's power deliberately towards individuals, groups or community thereby resulting in any type of injury but also includes violence against a person based on gender [1-3]. Globally, it has been incorporated into a different types of codes such as civil and criminal

(c) The Author(s). 2020 Open Access This article is licensed under a Creative Commons Attribution 4.0 International License, which permits use, sharing, adaptation, distribution and reproduction in any medium or format, as long as you give appropriate credit to the original author(s) and the source, provide a link to the Creative Commons licence, and indicate if changes were made. The images or other third party material in this article are included in the article's Creative Commons licence, unless indicated otherwise in a credit line to the material. If material is not included in the article's Creative Commons licence and your intended use is not permitted by statutory regulation or exceeds the permitted use, you will need to obtain permission directly from the copyright holder. To view a copy of this licence, visit http://creativecommons.org/licenses/by/4.0/ The Creative Commons Public Domain Dedication waiver (http://creativecommons.org/publicdomain/zero/1.0/) applies to the data made available in this article, unless otherwise stated in a credit line to the data. 
codes [3]. Gender-based violence is also defined as violence towards minority groups, individuals and/or communities solely based on their gender which can directly or indirectly result in psychological, physical and sexual traumas or injury as well as deprivation of their right as a human being [4].

The issue of gender-based violence has been existing for a long period and was detected in different socio-cultural and geographic areas [5]. The global conference on human rights that held in Vienna in 1993, delivered due concern to issues regarding female's lives, psychological integrity, physical bodies and liberty [6]. Further, other similar conferences also recognized GBV as an obstacle to the achievement of equity, development, and peace [7-9].

The physical and psychological consequences secondary to sexual violence are not only limited to the victims but also result in negative impacts on the society and communities as well [7-9]. Furthermore, GBV also hinders the daily life activities of women. Considering its socio-cultural impact on many aspects of life, it has been stated that "neglecting the offense is as equal as violating the fundamental right of human" and which is not acceptable, regardless of its occurrence [4-8]. Finding from an epidemiological study also suggested that GBV could affect female students' academic capabilities [10]. These could include poor or decreased attention to the class lectures, absent from the school and dropping out of their class. As a result, young girls are facing hindrances to continue their education as desired, affecting school enrolments, expected to yield and increased dropping outs from schools $[10,11]$.

Previous studies conducted in Ethiopia are a few in number and reported inconsistent results. For example, in some studies, the prevalence of GBV ranges between 34 and $65 \%$ [8-12]. Further, some of the factors suggested to be associated with GBV are not explicitly adjusted in different previous studies. However, per our knowledge no study has been conducted in the study area. Therefore, this study aimed to determine the prevalence and identify factors associated with gender-based violence among female students in Wolaita Sodo, Ethiopia.

\section{Methods}

\section{Study setting and population}

An Institutionally based-cross-sectional study was employed among high school female students in Wolaita Sodo, Ethiopia. Wolaita Sodo is the administrative capital city of Wolaita zone in Southern Ethiopia, which is found at $329 \mathrm{KM}$ of south of Addis Ababa, the capital city of Ethiopia. Based on the Ethiopian Demographic and Health Survey (EDHS) of 2011, it has the estimated population number of 76,050 . There are seven high schools in the town. The study was conducted between in May 2017 and June 2017.

\section{Sampling size and determination}

Single population proportion formula was used to calculate the required sample size using the lifetime prevalence of physical violence among high school female students (29\%) from the prior study mentioned elsewhere [13] considering 95\% CI and 5\% margin of error which resulted in a total of 633 students. We used a multi-stage stratified sampling techniques. First, the schools were stratified to private and public schools and then, we randomly selected four out of seven high schools. Proportion to population size sampling was used to allocate the students to their respective school and class. Lastly, systematic sampling technique was used to select students using students' roster (name list) as a sampling frame. The total students (age $\geq 15$ years) in each grade were divided by the allocated sample size for each grade to find the interval $(\mathrm{K})$ and the 1st female students in each class was selected randomly using the lottery method. Twenty-nine students (29) were excluded from the study due to serious illness during the data collection period. The details of the sampling methods mentioned in Fig. 1.

\section{Data collection instruments}

The data was collected by trained data collectors and supervised on daily basis. Gender-Based Violence assessment tool, validated by the World Health Organization and adapted to Ethiopian context, was used to assess gender-based violence and other determinants of GBV [14]. This assessment tool along with other questionnaires was developed in the English language and then translated to Amharic language and back to the English language to ensure convenient information was retrieved. The tool consisted of socio demographic/background characteristics, family history, history of substances use and sexual history. A pre-test study before the actual data collection was done at Bodit secondary high school students. Then, we modified the questionnaire based on the feedback. Over-all the data collection tool was highly reliable in our pre-test with Cronbach's alpha of 0.94 .

\section{Data processing and analyses}

Data were checked for completeness and entered into Epi Info version 7 and then exported to SPSS version 20 for further data cleaning and analysis. Frequency distributions were obtained to check for data entry error (missing/unrecognized values and codes). Descriptive statistics, tables, graphs, means, and frequency distribution was used to present the information. The presence of an association between the independent and outcome variable was checked by the Pearson chi-square test. Additionally, each independent variable was fitted separately into bivariate logistic analysis to evaluate for the degree of association with gender-based violence and to 


\section{high schools}

\section{private}
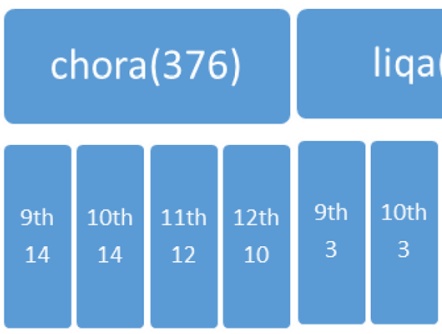

\section{be}

betlehem(436)
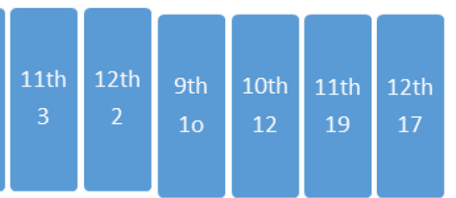

public

comprehensive( 3605)

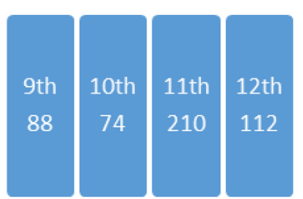

Fig. 1 Diagrammatic presentation of sampling procedure on prevalence, consequences and associated factors of GBV in adolescent female high school student in Sodo town, Wolayta Zone, June 2018

check any variability between private and public school students. Also, a further degree of association was assessed by multivariate logistic regression on variables with $p$-values less than 0.25 . The significance level was obtained with $95 \% \mathrm{CI}$ and $p$-value $<0.05$ to evaluate the degree of association between factors and GBV.

\section{Results}

\section{Socio-economic and demographic characteristics}

A total of 604 out of 633 students were participated in the study giving a response rate of $95.4 \%$. The mean age $( \pm \mathrm{SD})$ of the study participants was $17.08 \pm 1.5$ years. Of 604 students included in the study, 471 (78\%) were from public schools and 417 (69\%) were from Wolayta Sodo town. Among the respondents; 436 (72.2\%) were grown in an urban setting, 455 (75.3\%) were living with their parents, $26(4.3 \%)$ were married and 206 (34.1\%) had a boyfriend (Table 1).

\section{Family history}

Among students included this study; 438 (70.8\%) were whose mothers were attended formal education, 238 (39.4\%) reported that they were from families/guardian with good-income and 149 (24.7\%) witnessed parental violence as a child (i.e. their mothers were beaten by a husband or male partner when they were child) (Table 2).

\section{Substance abuse and related behaviors}

The lifetime history of chewing chat (khat, Catha edulis), smoking cigarette/tobacco, drinking alcohol and use of "ganja" was reported by 66 (10.9\%), 49 (8.1\%), $77(12.7 \%)$ and $32(5.3 \%)$ of the respondents respectively (Table 3$)$.

\section{Sexual experiences}

Of the total 604 students, 232 (28.4\%) had regular boyfriends and $115(19 \%)$ reported that they practiced sexual intercourse at least once in their life. The rate of involving in unintentional sexual intercourse was reported by 95 (79.2\%) of students that practiced sexual intercourse at least once in their life. The mean age $( \pm \mathrm{SD})$ for having the first sexual intercourse were found to be $15.8 \pm 1.5$ years and the mean age $( \pm \mathrm{SD})$ for with whom sexual intercourse did was $22.2 \pm 4.6$ years with an average of around 7 years above the participants (Table 4).

\section{The magnitude of GBV}

The lifetime prevalence of GBV, sexual violence, and physical violence were found to be $63.2,37.2$, and $56.3 \%$, respectively. Prevalence of GBV before joining the school, after joining the school and during the current academic year are 355(58.8\%), 288(47.7\%) and 254 (42.1\%) respectively. Prevalence of sexual violence before and after joining the current school and in the current academic year were $30.5,37.2$, and $22 \%$ respectively.

\section{Physical violence and implications}

Of all respondents, 341(56.3\%) reported physical violence once in their lifetime. Among respondents $306(50.7 \%)$ reported that violence happened before joining the school, 248 (41.1\%) after joining the school and 208 (34.4\%) sustained during this academic year (Fig. 2).

\section{Sexual violence}

The lifetime prevalence of sexual violence among female students was found to be $37.2 \%$, while sexual violence before joining the school, after joining the school and 
Table 1 Sociodemographic characteristics of high school female students included in the study, June 2017

\begin{tabular}{lllll}
\hline Variables & Public & Private & Total & Percent \\
\hline Age & & & & \\
$\leq 16$ & 169 & 55 & 214 & 35.5 \\
$17-18$ & 250 & 67 & 317 & 52.7 \\
$19-20$ & 52 & 11 & 63 & 10.4 \\
$\geq 21$ & 8 & 0 & 8 & 1.3
\end{tabular}

Place you lived before $12 \mathrm{yrs}$

$\begin{array}{lllll}\text { Country side } & 156 & 12 & 168 & 27.8 \\ \text { Town } & 315 & 121 & 436 & 72.2 \\ \text { Residence } & & & & \\ \text { Own house } & 318 & 122 & 440 & 72.8 \\ \text { Rental house } & 153 & 11 & 164 & 27.2 \\ \text { Alone } & 27 & 2 & 29 & 4.8\end{array}$

Living with

\begin{tabular}{|c|c|c|c|c|}
\hline Parents & 332 & 123 & 455 & 75.3 \\
\hline Husband/boyfriend & 13 & 3 & 16 & 2.6 \\
\hline Female friend & 48 & 3 & 51 & 8.4 \\
\hline Relative & 48 & 1 & 49 & 8.1 \\
\hline Other & 3 & 1 & 4 & 0.7 \\
\hline \multicolumn{5}{|l|}{ chool } \\
\hline Private & - & - & 133 & 22 \\
\hline Public & - & - & 471 & 78 \\
\hline \multicolumn{5}{|l|}{ irade } \\
\hline $9^{\text {th }}$ & 126 & 27 & 153 & 25.1 \\
\hline $10^{\text {th }}$ & 73 & 35 & 108 & 17.9 \\
\hline $11^{\text {th }}$ & 175 & 44 & 219 & 36.3 \\
\hline $12^{\text {th }}$ & 97 & 27 & 124 & 20.5 \\
\hline \multicolumn{5}{|l|}{ cademic performance } \\
\hline Good and above & 168 & 52 & 220 & 36.4 \\
\hline Average & 290 & 80 & 370 & 61.1 \\
\hline Poor & 13 & 1 & 14 & 2.3 \\
\hline \multicolumn{5}{|l|}{ larital status } \\
\hline Married & 25 & 1 & 26 & 4.3 \\
\hline Boy-friend & 176 & 30 & 206 & 34.1 \\
\hline None & 270 & 102 & 372 & 61.6 \\
\hline
\end{tabular}

the current academic year was reported as 184 (30.5\%), $147(24.3 \%)$ and $133(22 \%)$ respectively. The lifetime prevalence of complete rape was 112 (18.5\%). Similarly, the report of complete rape; before joining and after joining the school and the current academic year were reported as 69(11.4\%), $58(9.6 \%)$ and $32(5.3 \%)$ respectively (Table 5).

\section{Perpetrators of gender-based violence}

According to this study, the offenders of physical violence were family members /other relatives 177(50.2\%),
Table 2 Family history of high school female students included in the study, June 2017

\begin{tabular}{|c|c|c|c|c|}
\hline Variables & Public & Private & Total & Percent \\
\hline \multicolumn{5}{|c|}{ Father and mother Living together } \\
\hline Yes & 357 & 118 & 475 & 78.6 \\
\hline Divorced & 29 & 6 & 35 & 5.8 \\
\hline Mother alive & 43 & 5 & 48 & 7.9 \\
\hline Father alive & 21 & 3 & 24 & 4 \\
\hline Both dead & 21 & 1 & 22 & 3.6 \\
\hline \multicolumn{5}{|l|}{ Close family } \\
\hline Yes & 423 & 126 & 549 & 90.9 \\
\hline No & 48 & 7 & 55 & 9.1 \\
\hline \multicolumn{5}{|l|}{ Get support } \\
\hline Yes & 379 & 129 & 508 & 84.1 \\
\hline No & 92 & 4 & 96 & 15.9 \\
\hline \multicolumn{5}{|l|}{ Enough money } \\
\hline Yes & 271 & 99 & 370 & 61.3 \\
\hline No & 200 & 37 & 244 & 38.7 \\
\hline \multicolumn{5}{|l|}{ Family income } \\
\hline$\geq 127$ USD/month & 157 & 81 & 238 & 39.4 \\
\hline 32-127 USD/month & 199 & 43 & 242 & 40.1 \\
\hline$\leq 32$ USD/month & 115 & 9 & 124 & 20.5 \\
\hline \multicolumn{5}{|l|}{ Family control } \\
\hline Tight & 323 & 84 & 407 & 67.4 \\
\hline Average & 122 & 44 & 166 & 27.5 \\
\hline Poor & 26 & 5 & 31 & 5.1 \\
\hline \multicolumn{5}{|l|}{ Witnessing violence } \\
\hline Yes & 122 & 27 & 149 & 24.7 \\
\hline No & 349 & 106 & 455 & 75.3 \\
\hline \multicolumn{5}{|c|}{ Free discussion on reproductive issues } \\
\hline Yes & 211 & 50 & 261 & 43.2 \\
\hline No & 260 & 83 & 343 & 56.8 \\
\hline
\end{tabular}

students 66(18.7\%), teachers 45(12.7\%), husbands/boyfriends/partner 45(12.7\%) and strange 20(5.7\%). However, in case of perpetrators of sexual violence, the boyfriend/husband takes the lead $57(28.9 \%)$, family members/ other relatives $42(21.2 \%)$, students 39(19. 8\%), stranger $31(15.7 \%)$ teachers $20(10.2 \%)$. Therefore, the report suggested that 80 and $94 \%$ of perpetrators were known by the victims during sexual and physical violence respectively.

\section{Consequences of sexual violence}

There was lots of reported health, psychological and other complications associated with sexual violence. Complications like: rejection from family $37(25.5 \%)$, rejection from friends/peers 34 (23.4\%), poor academic achievement/ failure to continue the school 25(17.2\%), withdrawal from schools 22(15.2\%), alcohol dependency 
Table 3 History of substance use among high school students included in the study, June 2017

\begin{tabular}{|c|c|c|c|c|}
\hline Variables & Public & Private & Numbers & Percent \\
\hline \multicolumn{5}{|c|}{ Chew chat (khat, Catha edulis) } \\
\hline Yes & 57 & 9 & 66 & 10.9 \\
\hline No & 414 & 124 & 538 & 89.1 \\
\hline \multicolumn{5}{|c|}{ Cigarette Smoking } \\
\hline Yes & 43 & 4 & 49 & 8.1 \\
\hline No & 428 & 127 & 555 & 91.9 \\
\hline \multicolumn{5}{|c|}{ Alcohol drinking } \\
\hline Yes & 68 & 9 & 77 & 12.7 \\
\hline No & 403 & 124 & 527 & 87.3 \\
\hline \multicolumn{5}{|c|}{ Lifetime alcohol } \\
\hline Yes & 50 & 5 & 55 & 9.1 \\
\hline No & 421 & 128 & 549 & 90.9 \\
\hline \multicolumn{5}{|c|}{ Friend alcohol drink } \\
\hline Yes & 101 & 34 & 135 & 22.4 \\
\hline No & 370 & 99 & 459 & 77.6 \\
\hline \multicolumn{5}{|c|}{ Other Drugs } \\
\hline Yes & 30 & 2 & 32 & 5.3 \\
\hline No & 441 & 131 & 572 & 94.7 \\
\hline
\end{tabular}

Table 4 Sexual experiences among high school students included in the study, June 2017

\begin{tabular}{|c|c|c|c|c|}
\hline Variables & Public & Private & Total & Percent \\
\hline \multicolumn{5}{|c|}{ Regular boyfriend } \\
\hline Yes & 201 & 31 & 232 & 38.4 \\
\hline No & 270 & 103 & 372 & 61.6 \\
\hline \multicolumn{5}{|c|}{ Sexual intercourse } \\
\hline Yes & 105 & 10 & 115 & 19 \\
\hline No & 366 & 123 & 489 & 81 \\
\hline \multicolumn{5}{|c|}{ Age of sexual intercourse } \\
\hline$\leq 13$ & 4 & 1 & 5 & 43 \\
\hline $13-18$ & 96 & 7 & 103 & 89.6 \\
\hline$\geq 18$ & 5 & 2 & 7 & 6.1 \\
\hline \multicolumn{5}{|c|}{ Willingness at intercourse } \\
\hline Yes & 22 & 2 & 20 & 17.4 \\
\hline No & 83 & 8 & 95 & 82.6 \\
\hline \multicolumn{5}{|c|}{ More than one boyfriend } \\
\hline One & 131 & 29 & 160 & 58.4 \\
\hline Two & 47 & 3 & 50 & 18.3 \\
\hline Three & 23 & 4 & 27 & 9.9 \\
\hline$\geq$ four & 32 & 5 & 37 & 13.5 \\
\hline
\end{tabular}

9(6.2\%), having multiple sexual partners $7(4.8 \%)$, sexual dependency/abuse 6(4.1\%) and others 5 (3.4\%) (Fig. 3).

\section{Factors related to gender-based violence}

Initially, bivariate logistic regression was conducted to identify variables found to be associated with GBV. Next, multivariate logistic regression analysis was employed to identify factors associated with GBV (Table 6). Multivariate analysis indicated that a female who had boyfriends $(\mathrm{AOR}=2.022 ; 95 \% \mathrm{CI}: 1.08-3.79)$ and who are sexually active $(A O R=6.10 ; 95 \% C I$ : 2.49-14.92) were two and six times more faced GBV as compared to those who didn't have any sexual partner and start sexual intercourse respectively. Students who had female or male friends who drink alcohol were two times (AOR = 2.18; 95\% CI: $1.26-3.77)$ more likely to experience GBV when compared to their counter parts. Similarly, female students who witnessed their mothers were being beaten by their partners were more likely to experience GBV as compared to those who didn't witness any paternal violence $(\mathrm{AOR}=1.92 ; 95 \% \mathrm{CI}$ : 1.19-3.11). And also joining public school was found as a risk factor for GBV with $\mathrm{AOR}=1.74$ (95\% CI: 1.10-2.76).

\section{Discussion}

This study was conducted to investigate the prevalence and factors associated with gender-based-violence among female high school students in Wolaita Sodo, Ethiopia. The lifetime prevalence of gender-based violence, sexual violence, and physical violence was 63.8, 37.2 , and $56.2 \%$ respectively. The prevalence of GBV before joining the school, after joining the school and during the current academic year were 355 (58.8\%), 288 (47.7\%) and 254 (42.1\%) respectively.

The lifetime prevalence of gender-based-violence among female students was in agreement with other previous studies conducted in Ethiopia and the pooled estimated prevalence of gender-based violence among adolescents attending higher educations in sub-Saharan African countries [12, 15-18]. For example, a cross-sectional study conducted to assess the prevalence and factors associated with gender-based-violence among high school students residing in rural areas of Hadiya zone in Ethiopia reported $62.2 \%$ [15]. Further, a recent systematic review and metaanalysis that investigated the prevalence of gender-basedviolence among female students attending schools in subSaharan Africa also showed a much similar report [16]. However, the prevalence of GBV in this study was higher than the study conducted in Hawassa, Ethiopia that reported 24.4\% [19] and a result of a meta-analysis conducted in 2018 [20]. The lifetime prevalence of sexual violence among female students in the current study (37.2\%) was in-line with the findings from studies conducted in Ethiopia [16, 21, 22]. In contrast, an 


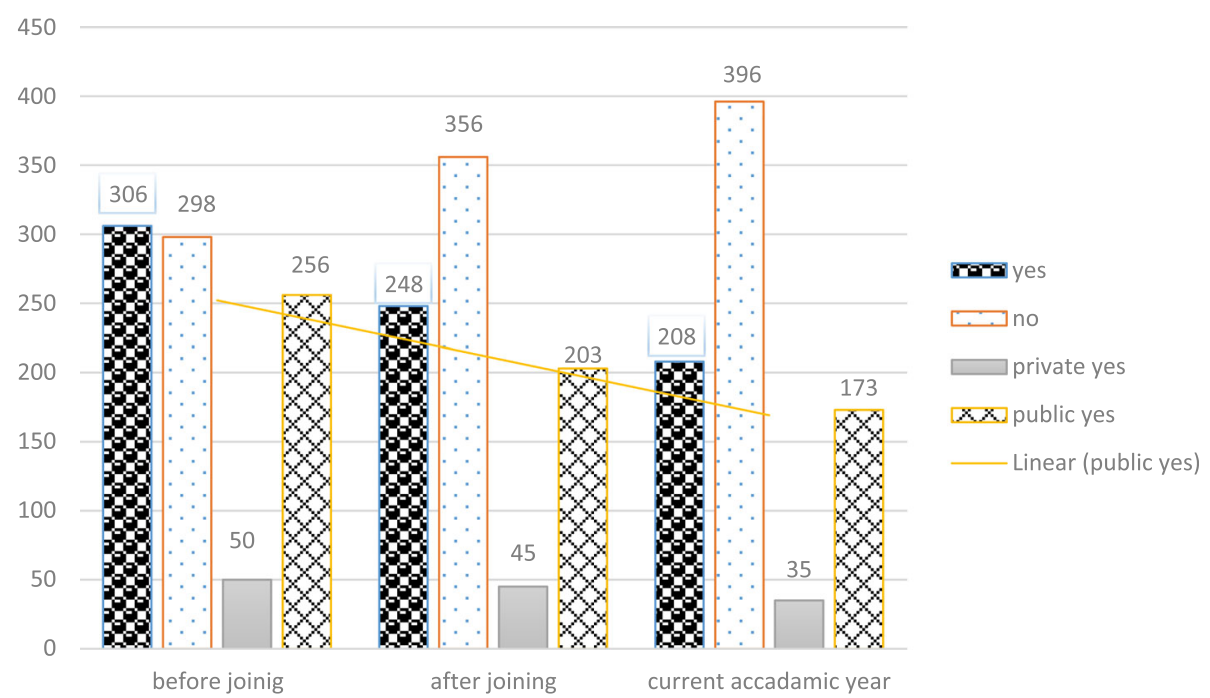

Fig. 2 Victims of physical violence among high school female students, June 2018

Table 5 Frequency and tendency of reporting rape among high school students included in the study, June 2017 ( $n=112)$

\begin{tabular}{lll}
\hline Variables & Total & Percent \\
\hline Number of rape & & \\
One & 48 & 42.9 \\
Two & 26 & 23.2 \\
Three & 20 & 17.8 \\
Four and above & 20 & 17.8 \\
Did you share to anybody & & \\
Yes & 41 & 36.6 \\
No & 71 & 63.4 \\
Whom did you share & & \\
Father & 7 & 17.1 \\
Mother & 19 & 46.3 \\
Sister & 11 & 26.8 \\
Brother & 3 & 7.3 \\
Other & 1 & 2.4 \\
Reported to a legal body & & \\
Yes & & 38.4 \\
No & 43 & 61.6 \\
Action taken & 18 & \\
Sentenced & 69 & 28.8 \\
Financial penalty & & \\
Forced to marry & & \\
\hline
\end{tabular}

institutionally-based-cross-sectional study that included female students from schools in Addis Ababa and Western Shewa to investigate the prevalence of sexual violence reported $74.4 \%$ [23]. This is also supported by finding from a study conducted among female students at Ambo University in Ethiopia that indicated $76.4 \%$ of female students have at least one incident of sexual coercion [24]. The lifetime and current prevalence of physical violence was 56.3 and $34.4 \%$ respectively. These findings were in agreement with the result of another community-based study [25]. However, these findings were lower than the results from the institution-based cross-sectional studies conducted in Debre Markos [17] and Jimma University students [13], but much higher than a study finding from Mekelle in Ethiopia that reported 26.4\% [18]. The variation in the prevalence of gender-based violence, sexual and physical violence may due to the difference in the study population (university students versus high-school students), socio-demographic characteristics, different definitions used for gender-based-violence, sexual and physical violence, sample size included in the study, datacollection methods used (self-administered versus interviewer-administered) and study design and setting (community-based versus institution-based).

Students who had regular boyfriends or partners were more likely to have gender-based violence when compared to their counterparts. This is also supported by a study conducted in Medawellabu University [26] and other studies mentioned elsewhere [25] which reported that a high prevalence of intimate partner violence. For example, a cross-sectional study conducted to investigate factors associated with sexual violence among female students reported a similar result [26]. This may be due to these students can spend time in private places where 


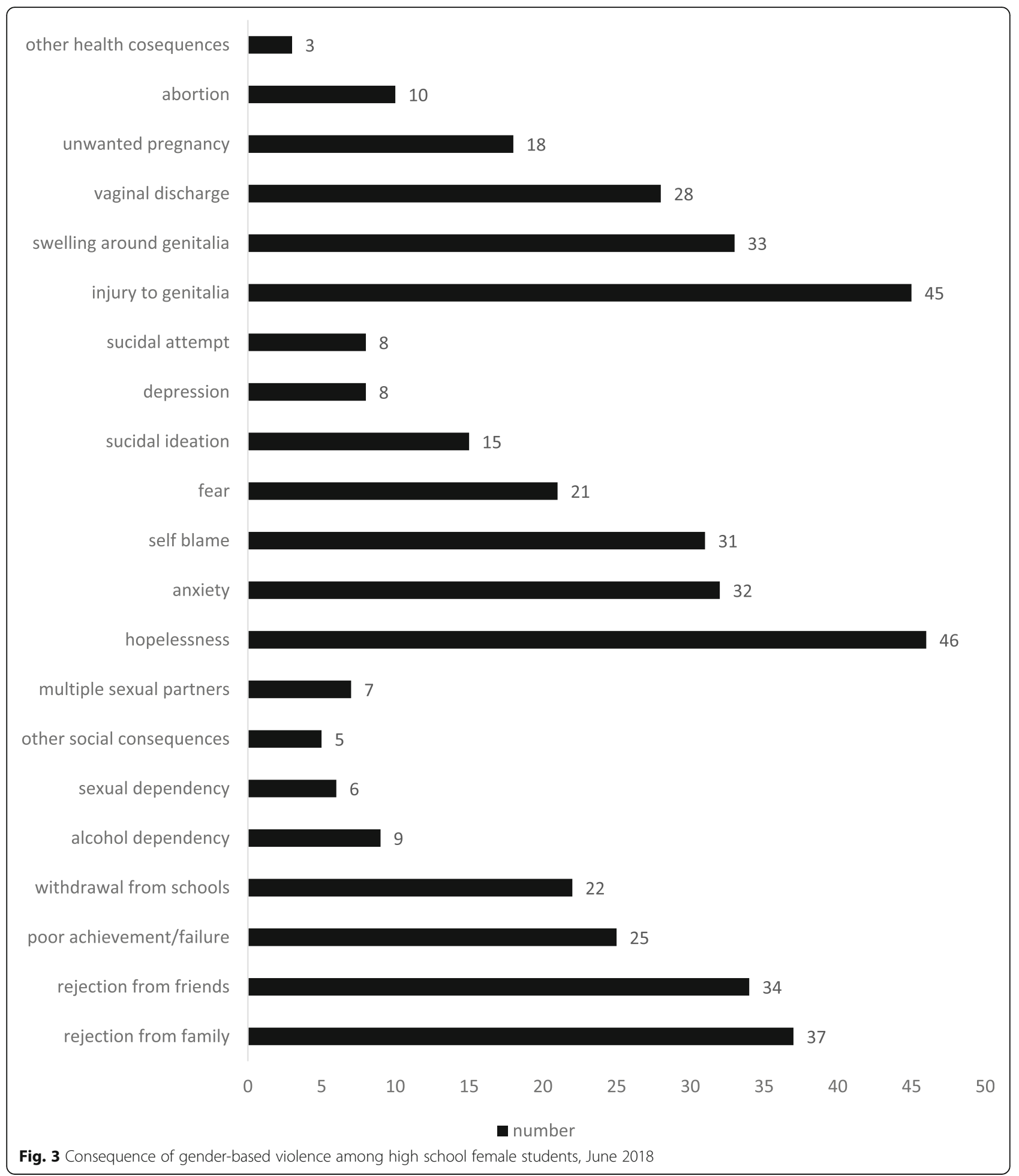

her boy-friend or partner forces them for unintentional sexual activity. This is also supported by studies that showed forced sexual activity is more likely to happen in the later stages of a dating relationship [27]. Additional studies also reported that the most frequently reported rapists to be a boyfriend or partner [28, 29].
The odds of having gender-based-violence were six and two times higher in students who witnessed their mothers being beaten by their partners or husband and started sexual intercourse when compared to those who did not respectively. This is also complemented by other previous studies that reported a strong association 
Table 6 Factors associated with GBV among high school students included in the study, June 2017

\begin{tabular}{|c|c|c|c|c|}
\hline \multirow[t]{2}{*}{ Variables } & \multicolumn{2}{|c|}{$\begin{array}{l}\text { GBV } \\
N=604\end{array}$} & \multirow[t]{2}{*}{$\begin{array}{l}\text { Crude odds ratio } \\
(95 \% \mathrm{Cl})\end{array}$} & \multirow[t]{2}{*}{$\begin{array}{l}\text { Adjusted odds } \\
\text { ratio( } 95 \% \mathrm{Cl})\end{array}$} \\
\hline & yes & no & & \\
\hline \multicolumn{5}{|l|}{ School } \\
\hline Public & 318 & 153 & $2.24(1.52,3.31)$ & $1.75(1.10,2.76)^{* *}$ \\
\hline Private & 64 & 69 & 1.00 & 1.00 \\
\hline \multicolumn{5}{|c|}{ Witnessing violence } \\
\hline Yes & 117 & 32 & $2.62(1.70,4.04)$ & $1.92(1.19,3.11)^{* *}$ \\
\hline No & 265 & 190 & 1.00 & 1.00 \\
\hline \multicolumn{5}{|c|}{ Chew chat (khat, Catha edulis) } \\
\hline Yes & 51 & 15 & $2.13(1.17,3.88)$ & $0.28(0.10,0.75)$ \\
\hline No & 331 & 207 & 1.00 & 1.00 \\
\hline \multicolumn{5}{|l|}{ Smoking } \\
\hline Yes & 46 & 3 & $9.99(3.07,32.53)$ & $4.16(0.93,18.54)$ \\
\hline No & 336 & 219 & 1.00 & 1.00 \\
\hline \multicolumn{5}{|c|}{ Lifetime alcohol } \\
\hline Yes & 53 & 3 & $11.50(3.55,37.29)$ & $3.30(0.62,17.51)$ \\
\hline No & 330 & 219 & 1.00 & 1.00 \\
\hline \multicolumn{5}{|c|}{ Friend alcohol use } \\
\hline Yes & 109 & 26 & $3.01(1.89,4.79)$ & $2.18(1.26,3.77)^{* *}$ \\
\hline No & 273 & 196 & 1.00 & 1.00 \\
\hline \multicolumn{5}{|c|}{ Regular boyfriend } \\
\hline Yes & 180 & 52 & $2.91(2.01,4.22)$ & $2.02(1.08,3.79)^{*}$ \\
\hline No & 202 & 170 & 1.00 & 1.00 \\
\hline \multicolumn{5}{|c|}{ Sexual intercourse } \\
\hline Yes & 106 & 9 & $9.09(4.49,18.37)$ & $6.10(2.49,14.93)^{* * *}$ \\
\hline No & 276 & 213 & 1.00 & 1.00 \\
\hline
\end{tabular}

Note:***- statistically significant at $p$-value $<0.001$; **- statistically significant at $p$-value $<0.01,{ }^{*}$ - statistically significant at $p$-value $<0.05$

between witnessing parental gender-based-violence during childhood period and gender-based-violence at their later adolescence ages [18, 26, 30,31]. A meta-analysis conducted to assess the association between child witnesses to domestic violence and child problems in the later age reported much similar result [32].

Students attending their classes at private schools were less likely to have physical violence when compared to their counterparts. This may be due to strictness of rules and obligations at private schools which is usually not the case in the public schools as well as poor management of students due to large number may be contributed to this variation.

The odds of having gender-based-violence were two times higher in students who had friends (male or female) drink alcohol when compared to students who did not have friends who drink either. This is consistent with findings from the studies in Mekele [18], Western Ethiopia and Addis Ababa University in which sexual violence was associated with having friends who drink alcohol [31, 33, 34]. Drinking alcohol could result in poor judgment and predispose female students to either physical violence or sexual violence.

This study also found that the social, physical and psychological consequences of gender-based-violence. Gender-basedviolence resulted in several social problems (rejection from the school and sexual dependency) and, health-related problems such as unwanted pregnancy, abortions, vaginal discharge, and injury to genitals and psychological complications such as self-blame, anxiety to the extent of having suicidal attempt. Further, family members/relatives and boyfriends/husbands take the frontline perpetrators of gender-based-violence which is in line with another previous study that suggested intimate partners were leaders in violence [35]. Although almost all perpetrators were known by the victims, less than $38 \%$ were brought to the legal body which calls for further interventions by stakeholders.

\section{Strength and limitation of the study}

The nature of the study design i.e. cross-sectional study, it will not tell us time association between the factors and the outcome variables. The burden of the problem may be underestimated since there are dropouts and absentee from the victims.

\section{Conclusion}

The prevalence of gender-based violence was high in the study area. This study recruited large sample size and hence it can be generalizable to other similar cities in the country. Having regular boy-friends, being sexually active, having female or male friends who drink alcohol, witnessed while their mothers being beaten by their partners and joining public school were significantly associated with gender-based-violence. This needs a due concern from governmental, non-governmental and civic organizations as well as other responsible bodies to tackle factors that are being identified in the study area. Further large scale studies incorporating male students are warranted to elucidate the factors associated with GBV in Ethiopia.

\section{Abbreviations \\ GBV: Gender-based violence; IPVAW: Intimate partner violence against women}

\footnotetext{
Acknowledgements

The authors appreciate the College of Medicine and Health Sciences, Hawassa University, Ethiopia for funding the study. We would like to thank respective high school directors, teachers and other staffs for their genuine help during data collection.

\section{Authors' contributions}

TT, SW and MT were responsible for the formulation and designing of the research topic, acquisition of data and data analysis, interpretation of results and drafting of the manuscript. MG and HM supervised the data collection process and data analysis, writing as well as the review of the drafted manuscript. BD involved in the analysis, write-up and drafting the manuscript as well as editing the document for proof reading. All authors had full access to all the data in the study and take responsibility for the integrity of the data and the accuracy of the analysis. All authors read and approved the final manuscript.
} 


\section{Funding}

The study data collection was funded by College of Medicine and Health Sciences, Hawassa University, Ethiopia. The funding body has no role in the design of the study and collection, analysis, and interpretation of data and in writing the manuscript.

\section{Availability of data and materials}

All relevant data are within the paper. Raw data can be accessible from the first and last author upon reasonable request.

\section{Ethics approval and consent to participate}

Ethical clearance was obtained from the Institutional Review Board (IRB) of College of medicine and health sciences, Hawassa University, Ethiopia with ethical clearance letter no. RPGe/98/2017. The IRB has given ethical clearance for both oral and written informed consent. Both oral and written informed consent was obtained from students after they were introduced to the purpose of the study and informed about their rights to interrupt the interview at any time. In addition, written informed consent was obtained from a parent or guardian for students under 16 years old. Confidentiality was maintained by using an anonymous questionnaire and privacy was assured.

\section{Consent for publication}

Not applicable.

\section{Competing interests}

The authors declare that they have no competing interests.

\section{Author details}

${ }^{1}$ School of medical sciences, Wolkite University, Wolkite, Ethiopia. ${ }^{2}$ Special Support Directorate, Federal Ministry of Health, Addis Ababa, Ethiopia. ${ }^{3}$ Wolaita Zone Health Department, Wolaita Sodo, Ethiopia. ${ }^{4}$ Faculty of Medical Sciences, College of Medicine and Health Sciences, Hawassa University, Hawassa, Ethiopia. ${ }^{5}$ Faculty of Health Sciences, College of Medicine and Health Sciences, Hawassa University, Hawassa, Ethiopia.

${ }^{6}$ School of Public Health, Curtin University, Perth, Australia.

Received: 27 September 2019 Accepted: 25 March 2020 Published online: 21 April 2020

\section{References}

1. Ellsberg M, Heise L. Researching violence against Women: a practical guide for researchers and activists. Washington DC: World Health Organization, PATH; 2005.

2. World Health Organization, the world health report 2002: reducing risks, promoting healthy life, 2002.

3. Joseph J. Sexual harassment in tertiary institutions: a comparative perspective. TEMIDA. 2015;18(2):125-44.

4. Assembly UG. Declaration on the elimination of violence against Women. UN General Assembly; 1993.

5. Women VA. A priority health issue. In: Family and Reproductive Health. Geneva: World Health Organization; 1997.

6. UN. United Nations, Vienna Declaration and Programme of Action adopted by the World Conference on Human Rights held in Vienna. 1993.

7. WHO. Women's Health and Domestic Violence against Women. Study Team, Prevalence of Intimate Partner Violence: findings from the WHO multi-country study on women's health and domestic violence. Lancet. 2006;368:1260-9.

8. WHO. Multi-country study on women's' health and domestic violence against women. Geneva: World Health Organization; 2005.

9. USAID. The effects of School-Related Gender-Based Violence on academic performance evidence from Botswana, Ghana \& South Africa. 2016.

10. USAID. Unsafe Schools: A Literature Review of School-Related Gender-Based Violence in Developing Countries.2003.

11. Terefe D, Mengistu D. Violence in Ethiopian schools: a study of some schools in Addis Ababa. Violence at school: global issues and interventions. Paris: UNESCO/IBE; 1997.

12. Beyene AS, Chojenta C, Roba HS, et al. Gender-based violence among female youths in educational institutions of sub-Saharan Africa: a systematic review and meta-analysis. Syst Rev. 2019;8:59.

13. Mamaru A, Getachew K, Mohammed Y. Prevalence of physical, verbal and nonverbal sexual harassments and their association with psychological distress among Jimma university female students: a cross-sectional study. Ethiop J Health Sci. 2015;25(1):29-38.

14. WHO multi-country study on women's health and domestic violence against women: summary report of initial results on prevalence, health outcomes and women's responses. 2005.

15. Letta T, Feleke A, Derseh L. Assessment of violence and associated factors among rural high school female students, in Hadiya zone, southern nation and nationalities peoples' region, Ethiopia, 2013. Open Access Library J. 2014;1(03):1.

16. Arnold D, Gelaye B, Goshu M, Berhane Y, Williams MA. Prevalence and risk factors of gender-based violence among female college students in Awassa, Ethiopia. Violence Vict. 2008;23(6):787-800.

17. Mullu G, Gizachew A, Amare D, Alebel A, Wagnew F, Tiruneh C, et al. Prevalence of gender-based violence and associated factors among female students of Menkorer high school in Debre Markos town, Northwest Ethiopia. Sci J Public Health. 2015;3(1):67-74 Science.

18. Yaynshet $G$. Prevalence and factors related to gender-based violence among female students of higher learning institutions in Mekelle town. Tigray: AAU; 2007.

19. Philpart M, Goshu M, Gelaye B, Williams MA, Berhane Y. Prevalence and risk factors of gender-based violence committed by male college students in Awassa, Ethiopia. Violence Vict. 2009;24(1):122-36.

20. Kassa GM, Abajobir AA. Prevalence of violence against Women in. Ethiopia: A Meta-Analysis. Trauma, Violence, \& Abuse; 2018. https://doi.org/10.1177/ 1524838018782205 .

21. Nimani W, Hamdela B, Sexual violence and associated factors among High School Students in Butajira Town, South Ethiopia. Gen Med Open Access. 2015:3:4. https://doi.org/10.4172/2327-5146.1000196.

22. Shimekaw B, Megabiaw B, Alamrew Z. Prevalence and associated factors of sexual violence among private college female students in Bahir Dar city, North Western Ethiopia. Health. 2013;5:1069-75. https:/doi.org/10.4236/health.2013.56143.

23. Mulugeta $E$, Kassaye M, Berhane Y. Prevalence and outcomes of sexual violence among high school students. Ethiop Med J. 1998:36(3):167-74.

24. Bekele T, Deressa W. Experience of Sexual Coercion and Associated Factors among Female Students of Ambo University in Ethiopia. Sci J Public Health. 2014;2(6):532-8. https://doi.org/10.11648/j.sjph.20140206.16.

25. Semahegn A, Mengistie B. Domestic violence against women and associated factors in Ethiopia; a systematic review. Reprod Health. 2015;12(1):1.

26. Bekele T, Kaso M, Gebremariam A, Deressa W. Sexual violence and associated factors among female students of Madawalabu University in Ethiopia. Epidemiol Open Access. 2015;2015.

27. United Nations. Division for the Advancement of Women, Department of Economic and Social Affairs. In: Secretary-General's In-Depth Study on Violence against Women. United Nations General Assembly, 61st Session: Advancement of Women; 2006. Available at: http://www.un.org/ womenwatch/daw/vaw/ Accessed February 1, 2017.

28. Gupta J, Falb KL, Lehmann H, Kpebo D, Xuan Z, Hossain M, Zimmerman C, Watts C, Annan J. Gender norms and economic empowerment intervention to reduce intimate partner violence against women in rural Cote d'Ivoire: a randomized controlled pilot study. BMC Int Health Hum Rights. 2013;13:46. https://doi.org/10.1186/1472-698X-13-46 [PMC free article] [PubMed].

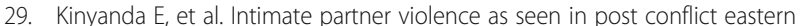
Uganda: prevalence, risk factors and mental health consequences. BMC Int Health Hum Rights. 2016;16:5 [PMC free article] [PubMed].

30. Tadesse S, Ali A, Deyessa N. Assessment of sexual coercion among Addis Ababa University female students. Gondar: 15th Annual Conference of the Ethiopian Public Health Association; 2004. p. 2004

31. Belayneh WN. Sexual Violence and Associated Factors among High School Students in Butajira Town, South Ethiopia. Gen Med Open Access. 2015;03(04).

32. Kitzmann KM, Gaylord NK, Holt AR, Kenny ED. Child witnesses to domestic violence: a meta-analytic review. J Consult Clin Psychol. 2003;71(2):339-52.

33. Misganaw AC, Worku YA. Assessment of sexual violence among street females in Bahir-Dar town, north West Ethiopia: a mixed method study. BMC Public Health. 2013;13(1):825.

34. Abeya SG, Afework MF, Yalew AW. Intimate partner violence against women in western Ethiopia: prevalence, patterns, and associated factors. BMC Public Health. 2011;11(1):913.

35. Gessessew A, Mesfin M. Rape and related helath problems in Adigrat zonal hospital, Tigray region, Ethiopia. Ethiop J Health Dev. 2004;18(3):140-4.

\section{Publisher's Note}

Springer Nature remains neutral with regard to jurisdictional claims in published maps and institutional affiliations. 